\title{
Endoscopic coil embolization of major intrahepatic biliary leak
}

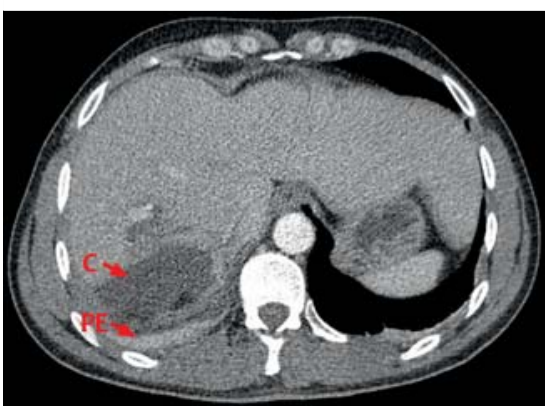

- Fig. 1 Initial abdomen CT showing a right pleural effusion and a subphrenic collection in the right hepatic lobe suggestive of a biliary leak. C, collection; PE, pleural effusion.

A 45-year-old man who had undergone surgery for a giant hepatic hydatid cyst 1 month ago presented to the emergency room with abdominal pain and fever. Computed tomography (CT) revealed a right pleural effusion and a collection in the right hepatic lobe, suggestive of a biliary leak (• Fig. 1).

After two failed endoscopic retrograde cholangiopancreatography (ERCP) attempts, the common bile duct (CBD) was punctured using a 22-G needle, and a 0.018 -in guidewire was advanced for an endoscopic ultrasonography-guided rendezvous. Cholangiography identified a major bile leak from one of the branches of the right main bile duct ( $>$ Fig. 2 ). An $80 \times 10-\mathrm{mm}$ fully-covered metal stent was inserted.

Given the lack of improvement, a second ERCP was performed showing the previous stent was in place. The leaking bile branch was selectively cannulated. Four 0.035-in Tornado coils (Cook Medical, Bloomington, Indiana, USA) were introduced through a retrieval balloon and deployed in the terminal end of the leaking duct. One of the coils was placed very distal in the biliary tree, so cholangioscopy was performed using SpyGlass (Boston Scientific Corp., Marlborough, Massachusetts, USA), and the coil was removed with a SpySnare (Boston Scientific Corp.)

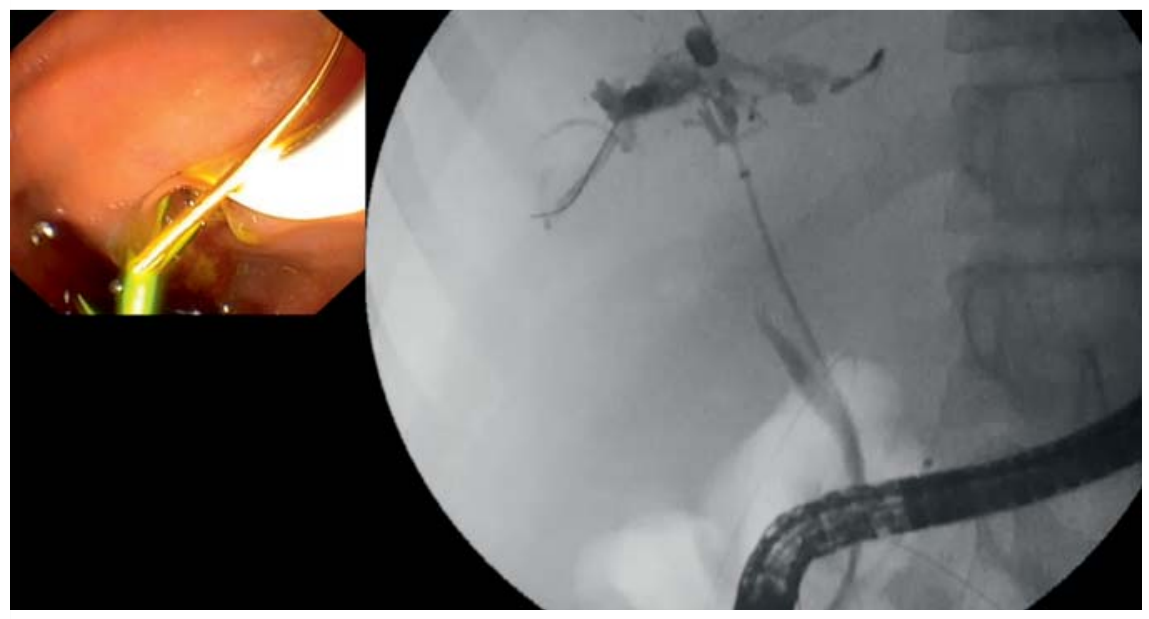

- Fig. 2 Endoscopic retrograde cholangiopancreatography showing a major bile leak from one of the branches of the right main bile duct.

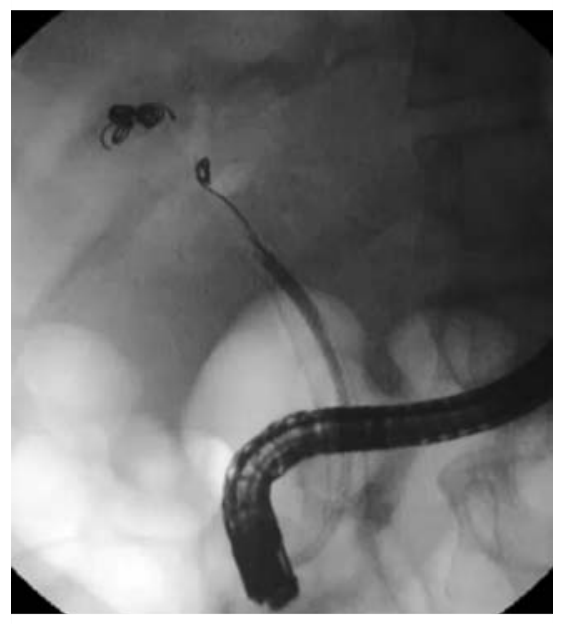

Fig. 3 Misplaced coil in the distal biliary tree retrieved with a snare through cholangioscopy.

( Fig.3). During cholangioscopy, a second leak was identified and later embolized with coils. A subsequent cholangiogram revealed cessation of the leaks ( Fig. 4; Video 1).

Six months after discharge, the patient presented with abdominal pain, and CT revealed a dilated $C B D$ with a migrated coil inside ( $\mathbf{F i g . 5}$ ). ERCP was performed and the coil extracted.

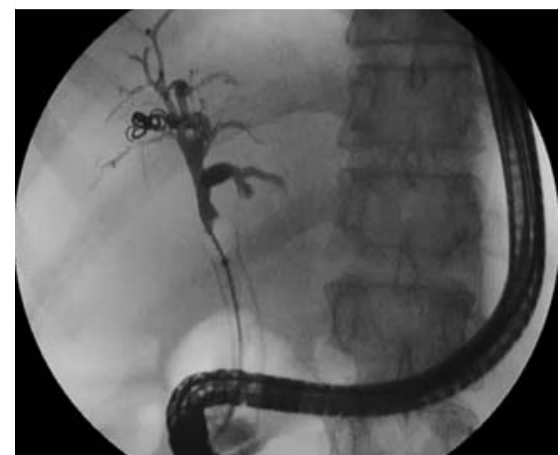

- Fig. 4 Post-coil embolization cholangiography revealing cessation of the biliary leak.

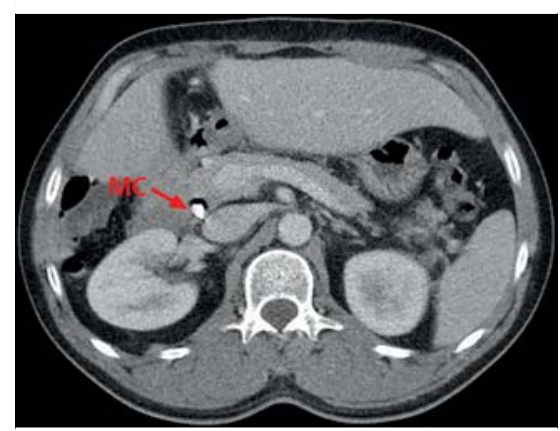

Fig. 5 Abdomen CT showing a migrated coil in the distal common bile duct. MC, migrated coil. 


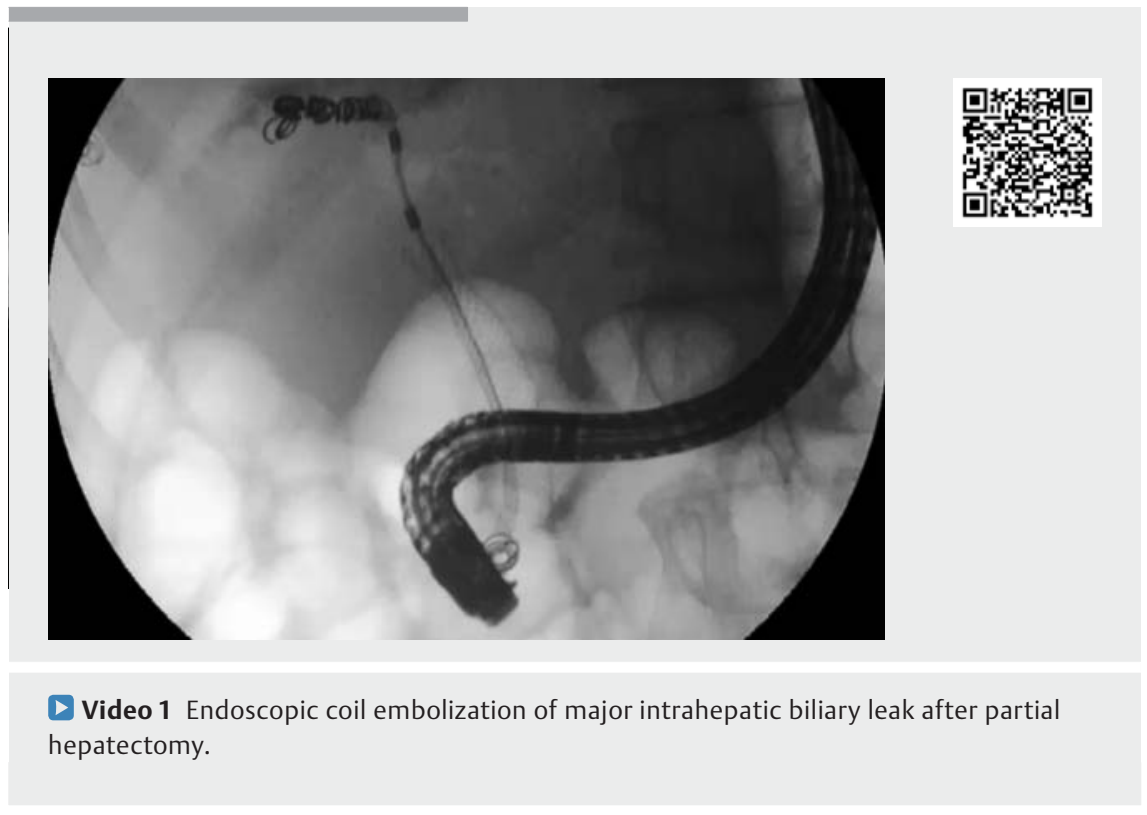

A bile leak is a serious complication after hepatobiliary surgery. Traditional endoscopic therapy consists of sphincterotomy or stent placement [1]. Endoscopic embolization with coils can be an alternative treatment of biliary leaks when other approaches fail [2,3]. Coil migration to the CBD is a complication that had already been described in coil embolization with or without N-butyl cyanoacrylate $[4,5]$

Endoscopy_UCTN_Code_TTT_1AR_2AG

\section{Competing interests}

Dr. Aparicio is a consultant for Boston Scientific. The other authors declare they have no conflict of interest.
The authors

Sandra Baile-Maxía, Lucía Medina-Prado, Maryana Bozhychko, Carolina Mangas-

Sanjuan, Juan Antonio Casellas, José Ramón Aparicio

Endoscopy Unit, Department of

Gastroenterology, Hospital General

Universitario de Alicante, Instituto de

Investigación Sanitaria y Biomédica de Alicante, ISABIAL, Alicante, Spain

Corresponding author

José Ramón Aparicio, MD

Hospital General Universitario de Alicante, Endoscopy Unit, C/ Pintor Baeza 12, 03010 Alicante, Spain Fax: Fax: +34-633-03-99-69

japariciot@gmail.com
[1] Sandha GS, Bourke M], Haber GB et al. Endoscopic therapy for bile leak based on a new classification: results in 207 patients. Gastrointest Endosc 2004; 60: 567-574

[2] Ganguly EK, Najarian KE, Vecchio JA et al. Endoscopic occlusion of cystic duct using $\mathrm{N}$-butyl cyanoacrylate for post-operative bile leakage. Dig Endoscopy 2010; 22: 348-350

[3] Schelhammer F, Vom Dahl S, Heintges T et al. Coil embolization for post-cholecystectomy bile leak. Cardiovasc Intervent Radiol 2007; 30: 529-530

[4] Wahaibi A, Alnaamani K, Alkindi A et al. A novel endoscopic treatment of major bile duct leak. Int J Surg Case Rep 2014; 5: 189192

[5] Sandroussi C, Lemech LD, Grunewald B et al. Late complication following coil embolization of a biliary leak. ANZ J Surg 2005; 75 : 614-615

\section{Bibliography}

DOI https://doi.org/10.1055/a-1113-7263

Published online: 4.3.2020

Endoscopy 2020; 52: E322-E323

(c) Georg Thieme Verlag KG

Stuttgart · New York

ISSN 0013-726X

\section{ENDOSCOPY E-VIDEOS}

https:/|eref.thieme.de/e-videos

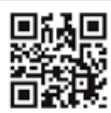

Endoscopy E-Videos is a free access online section, reporting on interesting cases and new

techniques in gastroenterological endoscopy. All papers include a high quality video and all contributions are freely accessible online.

This section has its own submission website at https://mc.manuscriptcentral.com/e-videos 